\title{
EL FUNDAMENTO CONSTITUCIONAL DE LA DETENCIÓN EN MATERIA DE EXTRADICIÓN INTERNACIONAL. ANÁLISIS DE LA CONSTITUCIONALIDAD DEL TRATADO DE EXTRADICIÓN Y ASISTENCIA MUTUA EN MATERIA PENAL ENTRE MÉXICO Y ESPAÑA*
}

[En abril de 2006, el pleno de la Suprema Corte de Justicia de la Nación (SCJN) resolvió el amparo en revisión 828 que tenía como objetivo el análisis del fundamento constitucional de la detención en materia de extradición internacional, concretamente: el análisis de la constitucionalidad del Tratado de Extradición y Asistencia Mutua en Materia Penal entre México y España. El caso ante la SCJN atrajo mucho la atención de la opinión pública nacional e internacional por tratarse de la extradición de ciudadanos vascos.

Desde el punto de vista jurídico, el caso tiene su importancia y complejidad pues se trata de determinar la constitucionalidad del Tratado de Extradición y Asistencia Mutua en Materia Penal entre México y España, asunto sumamente controvertido.

Desde el punto de vista político, el asunto significa un viraje de 180 grados de la política exterior del Estado mexicano que ha sido generosa en la admisión de los extranjeros que se han visto perseguidos, en sus países de origen, por sus ideas políticas.

Por supuesto que la sentencia dictada por la SCJN en el amparo 828 merece una estudio más amplio y profundo que estas líneas que sólo sirven de introducción al voto particular emitido por el ministro de la SCJN, José Ramón Cossío, en tan controvertido caso.**]

* El contenido de este documento derivó del voto particular que formuló el ministro José Ramón Cossío Díaz en el amparo en revisión 828/2005, promovido por María Asunción Gorrochategui Vázquez y otros. Se agradece el apoyo de la licenciada Lorena Goslinga Remírez para la elaboración de este documento.

[** Manuel Becerra Ramírez.] 
En sesiones de cuatro y seis de abril de dos mil seis, el Tribunal Pleno de la Suprema Corte de Justicia de la Nación resolvió el Amparo en Revisión 828/2005, en el sentido de modificar la sentencia recurrida; sobreseer en el juicio de garantías respecto de los artículos 16, 17, 18 y 22 de la Ley de Extradición Internacional, así como del artículo 19 del Tratado de Extradición y Asistencia Mutua en Materia Penal entre los Estados Unidos Mexicanos y el Reino de España, y negar el amparo y protección de la Justicia de la Unión a los quejosos, en los términos establecidos en los considerandos cuarto a décimo quinto de la propia ejecutoria.

En las votaciones correspondientes, expresé mi desacuerdo en torno al sobreseimiento decretado respecto de los artículos 17, 18 y 22 de la Ley de Extradición Internacional y 19 del Tratado de Extradición y Asistencia Mutua en Materia Penal entre los Estados Unidos Mexicanos y el Reino de España, en virtud de que no comparto la interpretación que se da en la sentencia mayoritaria al artículo 119 constitucional, misma que sirvió de base para fallar el sobreseimiento en cuestión.

Asimismo, me manifesté en contra de la constitucionalidad del Tratado de Extradición y Asistencia Mutua en Materia Penal entre los Estados Unidos Mexicanos y el Reino de España — específicamente de su artículo 15-y, por ende, me pronuncié a favor de la concesión del amparo a los quejosos.

A continuación expongo las consideraciones que sustentan mi voto en relación con ambos temas.

I. SOBRESEIMIENTO DECRETADO RESPECTO DE LOS ARTÍCULOS 17, 18

Y 22 DE LA LEY DE EXTRADICIÓN INTERNACIONAL Y 19 DEL TRATADO

DE EXTRADICIÓN Y ASISTENCIA MUTUA EN MATERIA PENAL

ENTRE LOS ESTADOS UNIDOS MEXICANOS Y EL REINO DE ESPAÑA

Según el criterio mayoritario, procede el sobreseimiento en el juicio respecto de los citados artículos, en razón de que dichas normas les fueron aplicadas a los quejosos en la orden de detención provisional y, por tanto, no son impugnables en amparo con motivo de la resolución final dictada en el procedimiento de extradición.

Lo anterior, debido a que, a su juicio, las violaciones que pudieran haberse cometido durante el trámite de la detención preventiva para efectos de extradición - cuyo fundamento encuentran en el artículo 119 constitucional- deben considerarse irreparablemente consumadas por virtud del cambio de situación 
jurídica que se apoya en la petición formal que da inicio al procedimiento de extradición seguido en forma de juicio.

Así, para la mayoría, la detención provisional es una medida precautoria que tiene por objeto evitar que la persona reclamada pueda sustraerse a la acción de la justicia, la cual queda superada con la petición formal de extradición que debe calificar la Secretaría de Relaciones Exteriores, en términos de los artículos 16, 19 y 21 de la Ley de Extradición Internacional; y más aún, con la detención formal por parte del juez de Distrito y con la resolución definitiva que concede la extradición.

No comparto el criterio mayoritario, ya que, como lo manifesté desde que se resolvió el Amparo en Revisión 1267/2003 — fallado en sesión de dieciséis de febrero de dos mil seis-, no coincido con la interpretación que se dio en la sentencia del artículo 119, tercer párrafo de la Constitución Política de los Estados Unidos Mexicanos.

En esa ocasión, expresé que, contrario a lo sostenido por la mayoría durante la discusión del asunto, en mi opinión, el tercer párrafo del artículo 119 constitucional establece un plazo único de hasta sesenta días para la detención de una persona con motivo de un procedimiento de extradición, reservándome mi derecho de formular voto concurrente, junto con el ministro José de Jesús Gudiño Pelayo.

Para exponer las razones que me llevan a diferir de la mayoría, en principio, es necesario mencionar algunas consideraciones sobre la evolución legislativa que ha tenido esta materia en nuestro sistema jurídico.

El diecinueve de mayo de mil ochocientos noventa y siete se publicó la Ley de Extradición, ${ }^{1}$ misma que fue derogada hasta mil novecientos setenta y cinco, con la Ley de Extradición Internacional que actualmente nos rige.

La Ley de Extradición de mil ochocientos noventa y siete tenía un capítulo segundo — que me parece sumamente interesante-, relativo a los procedimientos. El artículo 12 decía que la extradición se promovería siempre por la vía diplomática, mientras que en el artículo 13 se disponía que en casos de urgencia, la prisión provisional — esto en el contexto del tratado que se refiere a la detención provisional — podría acordarse por el Ejecutivo de la Unión.

Con base en esta ley, el Ejecutivo de la Unión era el facultado para acordar la detención provisional, previo pedimento del Estado requirente dirigido a él,

1 Véase Dublán, M. y Lozano, J. M., Legislación Mexicana o Colección Completa de las Disposiciones Legislativas Expedidas desde la Independencia de la República, México, 1898, t. XXVIII, p. 184. 
por correo o telégrafo, con expresión del delito, del aviso de estar decretada la prisión por autoridad competente y la promesa de reciprocidad, así como la presentación de la demanda con las pruebas de hecho y de derecho en que se fundara.

El artículo 14 del mismo ordenamiento disponía que si dentro del término prudente en el que se notificará al Estado solicitante - que nunca podría exceder de tres meses - no se presentara la demanda ante la Secretaría de Relaciones Exteriores, el detenido sería puesto en absoluta libertad y no se le volvería a aprehender por la misma causa. Por su parte, el artículo 17 decía que, recibida la demanda, se enviaría al juez de Distrito con los documentos que la acompañara, en cuya jurisdicción se encontrara el indiciado. Finalmente, el artículo 18 señalaba que la petición del gobierno extranjero y la orden de aprehensión de la Secretaría de Relaciones, dictada en los términos de esa ley, serían causa legal para que el juez de Distrito pronunciara auto motivado de prisión.

De la lectura de la Ley de Extradición de mil ochocientos noventa y siete, se advierte que las detenciones provisionales correspondían al Ejecutivo federal y, las detenciones denominadas "con fines de extradición", al Poder Judicial de la Federación. Así, se expresó en la exposición de motivos de esta ley:²

Entre los procedimientos que carecen de reglamentación en nuestro país, se encuentra el relativo a la extradición de criminales. Tenemos, en verdad, unos tratados sobre extradición, y otros dos que podrán llegar a Estado en breve, pero ni contiene no podían contener, en cuanto al modo de llevarlos a efecto, ciertas reglas que son indispensables, y que deberían estar fijadas en una ley a propósito; ley que, además de reglamentar las prevenciones de los tratados, tiene que marcar los trámites con que haya de verificarse una extradición cuando el gobierno la considere sin tratado, y sólo por razones conveniencia con arreglo al derecho internacional.

No existe semejante ley entre nosotros, como tampoco existe en muchas naciones aun de las más adelantadas, siendo pocas las que cuentan con una legislación previsora de este punto. Sin embargo, en nuestra república es de absoluta necesidad que la ley aclare en esta materia algunas dudas nacidas de la Constitución, o al menos de la inteligencia que suele darse a sus palabras. Su artículo 19 previene que: "Ninguna detención podrá exceder del término de tres días, sin que se justifique con un auto motivado de prisión y los demás requisitos que establezca la ley". El 15, en su segunda parte, prohíbe que se celebren convenios o tratados en virtud

2 Véase Proyecto de Ley de Extradición de Delincuentes de 28 de abril de 1897, Comisión de Relaciones Exteriores de la Cámara de Senadores del Décimo Octavo Congreso de la Unión. 
de los que se alteren o menoscaben las garantías y derechos que la constitución otorga al hombre y al ciudadano. Ahora bien: será muy raro el caso en que pueda prenderse a un hombre, para efectuar su extradición, y en menos de tres días este entregado al representante de la nación que lo reclame, y además fuera de nuestro territorio, siendo, por otra parte, inevitable que, transcurridos los tres días del arresto, pida amparo por la violación del citado artículo 19, o bien que cualquiera autoridad lo ponga libre, si es que no lo hace el alcalde de la prisión en cumplimiento de la ley primaria.

¿Cuál sería entonces el espíritu de la Constitución de 1857? Con toda evidencia fue que los Jueces pronunciaran un auto de prisión, motivado en el tratado mismo, en las pruebas que él pueda exigir o en la calificación del Ejecutivo, para justificar la prisión por más de tres días, de un individuo cuya extradición deba efectuarse. No hay otra explicación posible para combinar las absolutas prohibiciones que, por un lado, contienen el texto constitucional, con el consentimiento que, por el otro, se transparenta en él respecto a tratados de extradición. Es, por lo mismo, tan necesario, como conforme al espíritu de nuestro código fundamental, el que se expida una ley autorizando a los jueces para pronunciar su auto de prisión de modo que se cumplan los referidos tratados, y sin que se de margen a una queja fundada o especiosa, de que al cumplirlos se viola una garantía individual.

Bien sé que hay una ejecutoria muy respetable de la Suprema Corte, en la cual se ha declarado, con multitud de sólidos razonamientos y en consecuencia con uno de los votos del eminente jurisconsulto que preside ese Supremo Tribunal, que los citados artículos constitucionales no son aplicables a la materia de extradición, la que debe regirse exclusivamente por el derecho internacional. Ciertamente esa ejecutoria salva de pronto la dificultad; pero por desgracia, su existencia no es una garantía bastante de que en otro juicio la cuestión no será resuelta en sentido diferente, variación que ha ocurrido mas de una vez, y que acaso depende de la relativa novedad de ciertas cuestiones jurídicas entre nosotros, o de que la organización de la Corte, para definir amparos, se presta a frecuentes cambios en su personal.

Parece pues inconcusa la necesidad de remover la dificultad radicalmente, poniéndole cuanto antes el remedio, este no puede ser otro que el antes indicado, es decir, facultar a los jueces de un modo expreso para pronunciar el auto de prisión formal en virtud solo de lo que exija el caso de extradición.

Sobre los procedimientos para ésta, ocurren desde luego tres sistemas distintos: uno que podemos llamar judicial, otro exclusivamente administrativo, y un tercero que participa de ambos. El primero es observado en los dominios del gobierno británico y en los Estados Unidos, el segundo en todo el resto de las naciones conocidas con excepción de Bélgica y Holanda, donde se observa el tercero.

Consiste el judicial en hacer a los tribunales árbitros exclusivos, en cada caso, de si debe o no accederse a un pedimento de extradición. Al paso que este sistema de extradición pone mejor a cubierto las garantías del individuo, las cuales ordinariamente, y por la naturaleza de sus respectivas funciones, son mas acatadas 
ante un juez, que ante una autoridad del orden administrativo; al paso que ofrece esta ventaja, encierra el grave inconveniente de prestarse a todos los artificios del foro, envolviendo la cuestión sobre el cumplimiento de un tratado, cuestión que interesa las relaciones y puede afectar la seguridad de una nación, en el laberinto de un proceso, que los abogados suelen hacer interminable.

Por otra parte, los jueces, tan competentes para el derecho privado, no tienen los medios ni la posibilidad de apreciar las consideraciones de convivencia pública para conceder o negar una extradición en determinado caso. Por eso en la gran mayoría de los países civilizados, la extradición se considera, como un acto de alta administración, en que la razón política, o de Estado, debe siempre tomarse en cuenta. Así es que la decisión del asunto depende siempre en esos países del Poder Ejecutivo; el cual, estando encargado de conducir las relaciones exteriores, y siendo el que sigue las negociaciones para los tratados se haya en mejor posición para interpretarlos y darles el debido cumplimiento, puede mejor comprender su espíritu y de seguro se haya, con mejor aptitud para apreciar las ventajas o inconveniencias que resulten aplicables en uno $u$ otro sentido.

Queda pues, solamente por examinar el tercer sistema que, según hemos dicho, participa de los otros dos, y en verdad parece salvar los inconvenientes tanto del uno como el otro. Su esencia consiste en combinar la libertad del Ejecutivo para resolver si se lleva o no adelante una extradición, con la intervención de un tribunal que, en debate contradictorio con el Ministerio Público, siga las excepciones del acusado o presunto reo, y resuelva o dictamine sobre la aplicación del tratado. Los trámites con que al efecto debe procederse, están determinados en Bélgica por la ley del 15 de marzo de 1814, y en los Países Bajos por la ley del 13 de agosto de 1849.

Las mismas que antes se han expuesto para combatir los otros dos sistemas, militan a favor del que ahora se examina. Sería por lo mismo, prolongar innecesariamente esta exposición, el detenerse a hacer la aplicación de ellas en un sentido inverso, es decir, para defender el sistema que podemos llamar belga, ya que antes sirvieron para demostrar la inconveniencia del anglosajón, observado por el gobierno inglés y el de los Estados Unidos, así como para impugnar el francés o exclusivamente administrativo. Baste observar que en una excelente monografía sobre la extradición, escrita por un francés, el sistema belga es el que se prefiere, demostrando su superioridad con copia de razones y erudición oportuna. Me refiero al Tratado de la Extradición por Billot, París, 1874, p. 213.

Ese es también el sistema que se ha tomado por modelo en la iniciativa que, por acuerdo del Presidente, tengo la honra de presentar al Congreso de la Unión, de cuya sabiduría espero se sirva aprobarla, mejorándola con su elevado criterio. 
Por su parte, en el artículo 113 de la Constitución de 1857 sólo se refería a la obligación del Estado de entregar, sin demora, a los criminales de otros Estados a la autoridad que los reclamara. Lo anterior, era bastante ambiguo, pues no era claro si se hacía referencia a las extradiciones internas o externas. Así, el Constituyente de 1857 no hizo referencia a ningún término en materia de extradición, sino que éste derivaba de la Ley de Extradición de 1897.

En el caso del Constituyente de 1917, el texto original establecía que, en estos casos - haciendo referencia a la extradición entre Estados o en el extranjero-, el auto del juez que mandara cumplir la requisitoria de extradición sería bastante para motivar la detención por un mes, si se tratare de extradición entre los Estados, y por dos meses, cuando fuere internacional. Como se sabe, en mil novecientos noventa y tres este precepto se modificó, sustituyendo los términos de dos meses a sesenta días.

Con base en la evolución de nuestro orden jurídico en esta materia, considero que, contrario a la postura mayoritaria, las solicitudes de detención provisional que están planteadas en los preceptos legales que fueron aplicados a los quejosos, se refieren a la detención provisional que el Ejecutivo solicita con base en lo dispuesto en la carta de intención presentada por el país requirente, en tanto que la detención con fines de extradición es la prevista en el artículo 119 constitucional, misma que se solicita, igualmente, por la autoridad administrativa y se ejecuta por la autoridad jurisdiccional, una vez presentada la solicitud formal para ello.

De ahí que, en mi opinión, el hecho de que el párrafo tercero del artículo 119 constitucional no distinga periodos y únicamente hable de un sólo término, hable de sesenta días y mencione la palabra "hasta" sesenta días, quiere decir no más de sesenta días.

Por tanto, considero que se debió analizar en la sentencia la naturaleza de estos sesenta días, en virtud de que, desde mi punto de vista, éstos son plazos fatales, ya que ni el legislador ordinario ni ninguna autoridad están autorizados a prolongarlos, pues con base en los antecedentes legislativos, el Constituyente tuvo especial cuidado en regular, de manera limitada, todas las circunstancias en las que un gobernado pudiera ser privado de su libertad, señalando en cada caso concreto el término máximo que podría durar esa privación, sin que en ningún caso, esa atribución la haya delegado al legislador ordinario.

Así, por ejemplo, el artículo 16 establece que el Ministerio Público no podrá retener a un detenido más de cuarenta y ocho horas, salvo en caso de delincuencia organizada en que podrá duplicarse; el artículo 19, determina un plazo de setenta y dos horas, el cual solamente podrá ampliarse a petición del detenido; el 
artículo 21, se refiere a uno de treinta y seis horas para el arresto administrativo, y el artículo 119 señala sesenta días, para la extradición, que expresamente dice "hasta sesenta días", como plazo máximo.

Desde este punto de vista, lo que el artículo 119 constitucional autoriza en su tercer párrafo, son las detenciones con fines de extradición y no las detenciones provisionales. Por tanto, considero que el planteamiento central para resolver esta cuestión no consistía en determinar qué era lo que autorizaba la ampliación del plazo de detención provisional, sino más bien qué era lo que fundamentaba la detención provisional.

En mi opinión - reitero- la detención con fines de extradición está prevista en el artículo 119, tercer párrafo, de la Constitución; sin embargo, lo que no queda claro es ¿por qué una autoridad administrativa, así sea el presidente de la República, por sí o a través de su cancillería, puede solicitar a la autoridad jurisdiccional que se detenga provisionalmente a una persona hasta por sesenta días?

Tomando en cuenta la evolución de la historia legislativa y constitucional del país, encontramos el problema de determinar ¿dónde está el asidero constitucional de las detenciones provisionales? Evidentemente es más claro el fundamento de la detención definitiva por el juez respecto de un término de sesenta días, empero, lo que es más complejo de entender es cómo se puede privar a una persona o cómo se arraiga a una persona por sesenta días sin existir una petición formal por parte del Estado requirente.

De ahí que no comparta las consideraciones expresadas en la presente resolución, toda vez que, a mi modo de ver, en la sentencia se debió determinar cuál era el fundamento constitucional de estas detenciones provisionales que, insisto, no están previstas por el artículo 119 constitucional.

Asimismo, creo que el darle fuerza normativa a la Constitución es un asunto integral y no es un asunto en el que se analice un precepto y se exprese cómo debemos darle fuerza a éste con base en las demás disposiciones. La fuerza normativa, se debe entender en el sentido de que la Constitución se compone por un conjunto de preceptos de muy variada calidad, para efectos de darle su sentido pleno.

Desde esta perspectiva, es difícil introducir una distinción entre extraditables y no extraditables, en virtud de que las garantías individuales protegen - como lo señala el artículo 1o., párrafo primero- a todas las personas que habitan el territorio nacional, de manera que un extraditable tiene garantías individuales, precisamente porque habita en el territorio nacional, pues así fue como lo estableció el Constituyente.

Con base en lo anterior, si la persona reside aquí y se le va a aplicar un acto de autoridad, considero que sí tiene todo el derecho a que se le observen sus ga- 
rantías individuales, sin que en los alcances de esta observancia se plantee el problema de qué va a pasar afuera, es decir, si el comportamiento del país requerido será bueno o malo, si van cumplir o no con los compromisos internos, pues ello es un caso de responsabilidad internacional, competencia de la Corte Internacional de Justicia y no de la Suprema Corte de Justicia de la Nación mexicana.

Me parece que lo que le correspondía a esta Suprema Corte, además de lo ya mencionado, era la defensa de las garantías individuales de aquellos que sean detenidos por un acto de autoridad en un procedimiento de extradición, toda vez que éstos se encontraban en el territorio nacional, ello con base en dispuesto por el Constituyente de 1917.

En este sentido, y como lo mencioné líneas arriba, es claro cuál es el fundamento de la detención con fines de extradición, es decir, aquella ordenada judicialmente en términos del artículo 119 constitucional, la que podrá extenderse hasta por sesenta días. Sin embargo, no podemos decir lo mismo de aquella que se solicite por la autoridad administrativa de manera provisional, pues la Constitución sólo determina un plazo único de sesenta días.

Así, desde mi punto de vista, el artículo 119 prevé un periodo de detención con fines de extradición con fundamento en la determinación dictada por un juez, que puede extenderse hasta por sesenta días. Sin embargo, no existe fundamento constitucional para que la autoridad administrativa pueda solicitar detenciones provisionales, a partir de criterios puramente administrativos o de reciprocidad internacional, puesto que la Constitución no las prevé dentro de sus excepciones a los derechos fundamentales.

Por lo tanto, es al tenor de esas premisas que, en mi opinión, debió interpretarse el artículo 119, párrafo tercero constitucional, y en consecuencia, considero que no debió sobreseerse en el juicio respecto de los artículos 17, 18 y 22 de la Ley de Extradición Internacional y 19 del Tratado de Extradición y Asistencia Mutua en Materia Penal entre los Estados Unidos Mexicanos y el Reino de España, sino abordar su estudio y pronunciarse en torno a su constitucionalidad o inconstitucionalidad.

\section{CONSTITUCIONALIDAD DEL ARTÍCULO 15 DEL TRATADO \\ DE EXTRADICIÓN Y ASISTENCIA MUTUA EN MATERIA PENAL ENTRE LOS ESTADOS UNIDOS MEXICANOS Y EL REINO DE ESPAÑA}

De acuerdo con el criterio mayoritario, el artículo de referencia —en el que se prevén los documentos que deberán acompañarse a la solicitud de extradición de una persona-, no adolece de vicios de inconstitucionalidad, ya que el hecho 
de que su texto vigente no contemple como requisito para acceder a la extradición el que la orden de aprehensión o auto de prisión evidencien la existencia del delito y los indicios racionales de su comisión por el reclamado, en modo alguno conlleva a establecer que no se apega a la Constitución federal, o bien, que contravenga el artículo 15 de la propia norma fundamental.

En cambio, en mi opinión, debió haberse concedido la protección y amparo de la Justicia de la Unión a los quejosos por este concepto, en atención a los siguientes motivos:

Al resolver la Acción de Inconstitucionalidad 20/2003, por la que se declaró inconstitucional la figura de arraigo prevista en el artículo 122 bis del Código de Procedimientos Penales del Estado de Chihuahua, este pleno sostuvo que la Constitución Política de los Estados Unidos Mexicanos permite, excepcionalmente, la afectación de la libertad personal del gobernado mediante la actualización de las condiciones y los plazos que a continuación se enumeran:

a) En caso de delito flagrante obliga a quien realice la detención, a poner sin demora al indiciado o incoado a disposición de la autoridad inmediata y ésta al Ministerio Público, quien realizará la consignación.

b) En casos urgentes, tratándose de delitos graves y ante el riesgo fundado de que el indiciado se sustraiga a la justicia y no se pueda acudir ante un juez, el Ministerio Público puede realizar la detención bajo su responsabilidad, supuesto en que tendrá, ordinariamente, un plazo de 48 horas para poner al detenido a disposición de la autoridad judicial, la que de inmediato ratificará la detención o decretará la libertad.

c) Mediante orden de aprehensión dictada por autoridad judicial, quedando obligada la autoridad ejecutora a poner al inculpado a disposición del juez, sin dilación alguna y bajo su más estricta responsabilidad.

d) Por virtud de auto de formal prisión dictado por el juez de la causa, dentro del improrrogable plazo de 72 horas a partir de que el indiciado sea puesto a su disposición.

e) Tratándose de sanciones por infracciones a los reglamentos gubernativos y de policía, se permite el arresto hasta por 36 horas.

A estos cinco supuestos para la afectación de la libertad personal previstos en la Constitución agregaría yo la detención a que se refiere el artículo 119 constitucional, en cuyo tercer párrafo se establece que:

Las extradiciones a requerimiento de Estado extranjero serán tramitadas por el Ejecutivo federal, con la intervención de la autoridad judicial en los términos de esta Constitución, los tratados internacionales que al respecto se suscriban y las le- 
yes reglamentarias. En esos casos, el auto del juez que mande cumplir la requisitoria será bastante para motivar la detención hasta por sesenta días naturales.

Es decir, agregaría la detención de hasta por sesenta días naturales prevista en el artículo 119 constitucional, la cual, en mi opinión, debe cumplir también con ciertas condiciones para ser acorde con las garantías de libertad personal, legalidad y seguridad jurídica consagradas en la Constitución federal.

Esto es así ya que, con independencia de que se trate de una detención derivada de un procedimiento de naturaleza penal o administrativa (como acontece en el caso que nos ocupa), de una interpretación sistemática de los artículos 15 y 119 constitucionales, se desprende que en México está prohibida la celebración de tratados para la extradición, en virtud de los que se alteren las garantías y derechos establecidos por la Constitución para el hombre y el ciudadano.

Ahora bien, ¿qué condiciones mínimas deben satisfacerse en el caso de la detención a que se refiere el artículo 119? Desde mi perspectiva son las siguientes:

1. Que la detención no se funde en una ley privativa o en una resolución emitida por un tribunal especial (artículo 13).

2. Que la detención se dé con motivo de un juicio que se seguirá o fue seguido ante tribunales previamente establecidos, en el que se cumplan las formalidades esenciales del procedimiento y conforme a las leyes expedidas con anterioridad al hecho (artículo 14).

3. Que la detención no se funde en un tratado para la extradición de reos políticos o de aquellos delincuentes del orden común que hayan tenido en el país donde cometieron el delito, la condición de esclavos (artículo 15).

4. Que la detención se lleve a cabo en virtud de mandamiento escrito de la autoridad competente, que funde y motive la causa legal del procedimiento (artículos 16, primer párrafo, y 119, tercer párrafo).

5. Que existan datos que acrediten el cuerpo del delito por el que se solicita la extradición y que hagan probable la responsabilidad del extraditable (artículo 16 , segundo párrafo).

6. Que la autoridad que ejecute la detención, ponga al extraditable a disposición del juez, sin dilación alguna y bajo su más estricta responsabilidad (artículo 16 , tercer párrafo).

7. Que la detención se dé con motivo de una solicitud de extradición por la comisión de un delito que merezca pena corporal (artículo 18).

8. Que la detención no se dé con motivo de una solicitud de extradición por la comisión de un delito por el que ya haya sido juzgado el extraditable (artículo 23). 
Lo anterior, tomando en consideración que, como ya señalé, aun cuando no se trate de una detención penal, las garantías de libertad personal, legalidad y seguridad jurídica consagradas en la Constitución tienen plena vigencia en estos casos, ya que el propio artículo 119 señala que las extradiciones a requerimiento de Estado extranjero serán tramitadas por el Ejecutivo federal, con la intervención de la autoridad judicial en los términos de la Constitución, los tratados internacionales que al respecto se suscriban y las leyes reglamentarias.

En consecuencia, en el presente caso considero que lo que procedía era analizar si el Tratado de Extradición y Asistencia Mutua en Materia Penal, entre los Estados Unidos Mexicanos y el Reino de España, en general, y su artículo 15, en lo particular, satisfacen o no las condiciones a que he hecho alusión.

A partir de una revisión del texto actual del tratado de extradición en cuestión, se advierte que la condición que mencioné en primer término, es decir, que la detención no se funde en una ley privativa o en una resolución emitida por un tribunal especial, se satisface en los artículos 2, numeral 1; 13, y 15, apartado 1 , inciso c), del tratado. ${ }^{3}$

Por su parte, la segunda condición, consistente en que la detención se dé con motivo de un juicio seguido ante los tribunales previamente establecidos, en el que se cumplan las formalidades esenciales del procedimiento y conforme a las leyes expedidas con anterioridad al hecho, se satisface en los artículos 2, apartado $1 ; 10 ; 11 ; 13$, y 17 , apartado $1 .{ }^{4}$

3 Los artículos en comento son del tenor literal siguiente: “Artículo 2. 1. Darán lugar a la extradición los hechos sancionados según las leyes de ambas partes, con una pena privativa de libertad cuyo máximo no sea inferior a un año./... Artículo 13. La persona objeto de extradición no podrá ser sometida en el territorio de la parte requirente a un tribunal de excepción. No se concederá la extradición para ello ni para la ejecución de una pena impuesta por tribunales que tengan ese carácter./... Artículo 15. Con la solicitud de extradición se enviará... c) texto de las disposiciones legales relativas al delito o delitos de que se trate, penas correspondientes y plazos de prescripción".

4 Los artículos 10, 11 y 17 establecen textualmente lo siguiente: "Artículo 10. No se concederá la extradición cuando la responsabilidad penal se hubiere extinguido por prescripción u otra causa, conforme a la legislación de cualquiera de las partes./ Artículo 11. Si el reclamado hubiese sido condenado en rebeldía, la extradición sólo se concederá si la parte requirentes (sic) da seguridades de que será oído en defensa y se le facilitarán los recursos legales pertinentes./... Artículo 17. 1. El individuo entregado en virtud de extradición no será procesado, juzgado o detenido para la ejecución de una pena por un hecho anterior y diferente al que hubiese motivado la extradición, salvo en los casos siguientes: a) Cuando la parte que lo ha entregado preste su consentimiento, después de la presentación de una solicitud en este sentido, que irá acompañada de los documentos previstos en el artículo 15 y de una declaración de la persona entregada formulada ante 
La tercera condición, esto es, que la detención no se funde en un tratado para la extradición de reos políticos o de aquellos delincuentes del orden común que hayan tenido en el país donde cometieron el delito, la condición de esclavos, se satisface en el artículo 4 del tratado. ${ }^{5}$

Las condiciones cuarta y sexta, relativas a que la detención se lleve a cabo en virtud de mandamiento escrito de la autoridad competente, que funde y motive la causa legal del procedimiento y a que la autoridad que ejecute la detención, ponga al extraditable a disposición del juez, sin dilación alguna y bajo su más estricta responsabilidad, respectivamente, se satisfacen en el artículo en el artículo 19 del tratado, ${ }^{6}$ en relación con el tercer párrafo del artículo 119 constitucional.

las autoridades competentes de la parte requirente. b) cuando, estando en libertad de abandonar el territorio de la parte a la que fue entregado, el inculpado haya permanecido en él más de cuarenta y cinco días sin hacer uso de esa facultad".

5 El artículo 4 dispone que: "Artículo 4. 1. No se concederá la extradición por delitos considerados como políticos o conexos con delitos de esta naturaleza. La sola alegación de un fin o motivo político en la comisión de un delito no le calificará por sí mismo como un delito de carácter político. A los efectos de este tratado, en ningún caso se considerarán delitos políticos: a) el atentado contra la vida de un jefe de Estado o de gobierno o de un miembro de su familia; b) los delitos comprendidos en tratados multilaterales que impongan a las partes, en caso de no conceder la extradición, someter el asunto a sus propias autoridades judiciales. Entre otras, las infracciones comprendidas en el ámbito de aplicación de los siguientes tratados: Convenio para la Represión del Apoderamiento Ilícito de Aeronaves, firmado en La Haya, el 16 de diciembre de 1970; Convenio para la Represión de Actos Ilícitos contra la Seguridad de la Aviación Civil, firmado en Montreal, el 23 de septiembre de 1971; Protocolo para la Represión de Actos Ilícitos de Violencia en los Aeropuertos que presten Servicios a la Aviación Civil Internacional, hecho en Montreal, el 24 de febrero de 1988; Protocolo para la Represión de Actos Ilícitos contra la Seguridad de las Plataformas Fijas Emplazadas en la Plataforma Continental, hecho en Roma, el 10 de marzo de 1988. c) Los actos de terrorismo. 2. Tampoco se concederá la extradición si la parte requerida tiene fundados motivos para suponer que la solicitud de extradición motivada por un delito común ha sido presentada con la finalidad de perseguir o castigar a un individuo a causa de su raza, religión, nacionalidad u opiniones políticas o bien que la situación de este individuo puede ser agravada por estos motivos".

6 Este artículo establece lo siguiente: "Artículo 19. 1. En caso de urgencia, las autoridades competentes de la parte requirente podrán solicitar la detención preventiva del individuo reclamado. La solicitud de detención preventiva indicará la existencia de una de las resoluciones mencionadas en el apartado b) del artículo 15 y la intención de formalizar la solicitud de extradición. Mencionará igualmente la infracción, el tiempo y el lugar en que ha sido cometida y los datos que permitan establecer la identidad y nacionalidad del individuo reclamado. 2. La solicitud de detención preventiva será 
La séptima condición, relativa a que la detención se dé con motivo de una solicitud de extradición por la comisión de un delito que merezca pena corporal, se satisface en los artículos 1 y 2 del tratado. ${ }^{7}$

Igualmente, la octava condición, consistente en que la detención no se dé con motivo de una solicitud de extradición por la comisión de un delito por el que ya haya sido juzgado el extraditable, se encuentra satisfecha en el artículo 9 del tratado, en el que se dispone que la extradición no será concedida si el individuo ha sido ya juzgado por las autoridades de la parte requerida por los mismos hechos que originaron la solicitud.

En cambio, la condición a que hice alusión en quinto lugar, es decir, que existan datos que acrediten el cuerpo del delito por el que se solicita la extradición y que hagan probable la responsabilidad del extraditable, no se satisface en ningún artículo del tratado.

En efecto, como se advierte de la revisión del Tratado de Extradición celebrado con el Reino de España, en especial de su artículo 15, que es en el que se

transmitida a las autoridades competentes de la parte requerida, por la vía más rápida, pudiendo utilizar cualquier medio de comunicación siempre que deje constancia escrita o esté admitido por la parte requerida. 3. Al recibo de la solicitud a que se refiere el apartado 1, la parte requerida adoptará las medidas conducentes a obtener la detención del reclamado. La parte requirente será informada del curso de su solicitud. 4. Podrá concederse la libertad provisional siempre que la parte requerida adopte todas las medidas que estime necesarias par (sic) evitar la fuga del reclamado. 5. La detención preventiva podrá alzarse si en el plazo de cuarenta y cinco días la parte requerida no ha recibido la solicitud de extradición y los instrumentos mencionados en el artículo 15. En ningún caso podrá exceder de un plazo de sesenta días. 6. La puesta en libertad no impedirá el curso normal del procedimiento de extradición si la solicitud y los documentos mencionados en el artículo 15 se llegan a recibir posteriormente".

7 Los artículos 1 y 2 son del tenor literal siguiente: "Artículo 1. Las partes contratantes se obligan a entregarse recíprocamente, según las reglas y bajo las condiciones determinadas en los artículos siguientes, los individuos contra los cuales se hayan iniciado un procedimiento penal o sean requeridos para la ejecución de una pena privativa de libertad impuesta judicialmente como consecuencia de un delito./ Artículo 2. 1. Darán lugar a la extradición los hechos sancionados según las leyes de ambas partes, con una pena privativa de libertad cuyo máximo no sea inferior a un año. 2. Si la extradición se solicita para la ejecución de una sentencia se requerirá, además, que la parte de la pena que aun falte por cumplir no sea inferior a seis meses. 3. Si la solicitud de extradición se refiere a varios hechos distintos, castigado cada uno de ellos por las leyes de ambas partes con pena privativa de libertad o con pena de multa, pero alguno de ellos no cumpliese el requisito relativo a la duración mencionada de la pena privativa de libertad, la parte requerida tendrá la facultad de conceder también la extradición por dichos hechos". 
contempla la información y documentación que deberá enviarse con la solicitud de extradición, no se exige en ninguno de sus apartados que deba acompañarse información que permita a las autoridades del país requerido concluir que existen elementos que hagan probable la comisión del delito y la responsabilidad del reclamado en ella.

Lo mismo sucede en el caso del artículo 19, apartado 1, en el cual se establece la posibilidad de que se realice la detención preventiva del individuo reclamado, en los términos siguientes:

1. En caso de urgencia, las autoridades competentes de la parte requirente podrán solicitar la detención preventiva del individuo reclamado. La solicitud de detención preventiva indicará la existencia de una de las resoluciones mencionadas en el apartado b) del artículo 15 y la intención de formalizar la solicitud de extradición. Mencionará igualmente la infracción, el tiempo y el lugar en que ha sido cometida y los datos que permitan establecer la identidad y nacionalidad del individuo reclamado.

Al respecto, cabe destacar que, con anterioridad a la entrada en vigor del protocolo de 23 de junio de 1995, esta situación era distinta, ya que el artículo 15 a que hemos hecho referencia disponía, en la parte final del apartado b), que con la solicitud debería enviarse original o copia de la resolución de la que se desprendiera la existencia del delito y los indicios racionales de su comisión por el reclamado.

Sin embargo, toda vez que el texto vigente del tratado, ya no incluye dicha indicación y, por ende, su texto permite que ordene la detención de una persona $y$, en su caso, se conceda su extradición, sin contar con elementos que permitan acreditar el cuerpo del delito y la probable responsabilidad del extraditable en su comisión, lo cual resulta violatorio de la garantía de libertad personal consagrada en Constitución Política de los Estados Unidos Mexicanos, es que, en mi opinión, debió declararse la inconstitucionalidad de los artículos 15 y 19 del tratado de extradición y, en consecuencia, concederse el amparo y protección de la justicia federal solicitados por los quejosos.

Lo anterior, insisto, en virtud de que la detención provisional para fines de extradición prevista en el 119, debe ser relacionada con el resto del ordenamiento constitucional, pues en caso contrario (como se resolvió en el pleno), se está tomando dicha disposición en sentido autónomo y se está dejando una modalidad de detención fuera del entendimiento constitucional. Del artículo 119, desde una interpretación sistemática, se desprende que es necesario acatar lo que la propia Constitución dispone, de ahí que los requisitos previstos en cualquier tra- 
tado internacional en materia de Extradición deban ajustarse a los parámetros previamente establecidos en aquélla.

Si el artículo 119 constitucional nos ordena que verifiquemos las garantías individuales que se refieren a detención y el tratado internacional entre México y España omite ciertas garantías, este último está modificando nuestras libertades fundamentales.

Un tribunal constitucional, de cualquier país en general, procede primordialmente a aplicar su derecho nacional. Al haber protestado nosotros —en nuestro carácter de ministros de la Suprema Corte_-, guardar y hacer guardar la Constitución Política de los Estados Unidos Mexicanos y las leyes que emanen de ella, estamos obligados a contrastar los tratados internacionales con la Constitución, en términos del artículo 133 de la norma fundamental, para ver si satisfacen o no las condiciones que nuestra máxima ley dispone.

Por tanto, aun cuando la Convención de Viena señala que los Estados no podrán invocar su derecho interno para oponerse al cumplimiento de los tratados que celebren, en mi opinión, el Estado mexicano y, en particular la Suprema Corte de Justicia de la Nación, deben salvaguardar la supremacía de la Constitución, no obstante que pudiera llegarse a generar responsabilidad internacional.

Nos encontramos frente a la preservación de derechos fundamentales. La Suprema Corte de Justicia debe estar dispuesta a declarar la inconstitucionalidad de un tratado que los vulnere, aun a sabiendas de que dicha decisión podría generar la responsabilidad del Estado mexicano.

Esto, en razón de que tanto el artículo 15 como el 19 del Tratado de Extradición y Asistencia Mutua en Materia Penal entre los Estados Unidos Mexicanos y el Reino de España no satisfacen el estándar de constitucionalidad necesario para llevar a cabo la detención de los habitantes del territorio nacional.

Así, no es que se lleve a cabo una aplicación extraterritorial del derecho mexicano al juzgar de inconstitucional un tratado internacional, sino que se está garantizando la supremacía de nuestra Constitución respecto de los actos que, aunque provenientes de autoridades extranjeras, pretenden tener efectos en México.

El Estado mexicano no está determinando ningún efecto jurídico respecto del ordenamiento jurídico español, sino que condiciona el requerimiento de extradición de un individuo que se encuentre en territorio nacional a ciertos requisitos: los derechos fundamentales. De ahí que, si al contrastar dicha petición con nuestra ley suprema, no se satisfacen sus pretensiones, el Estado mexicano no esté en condiciones de detener a la persona y enviarla al país requirente.

No es que pueda haber violaciones graves o no graves al derecho internacional; la Convención de Viena no nos permite hacer esa distinción: el Estado 
mexicano incurriría invariablemente en responsabilidad por falta de cumplimiento al tratado. Sin embargo, esta es la disyuntiva que se les presenta todos los días a los tribunales constitucionales de los Estados nacionales: el aplicar su derecho nacional o el derecho internacional, debiéndose, desde mi punto de vista, optar por la satisfacción de los derechos fundamentales previstos en la Constitución Política de los Estados Unidos Mexicanos, incluso a riesgo de incurrir en responsabilidad.

José Ramón Cossío DÍAZ*

* Ministro de la Suprema Corte de Justicia de la Nación. 